\title{
The Perceived Role of "Igbe" Religious Practice in the Development of Mental Illness among the Tiv People of Benue State Nigeria
}

\author{
Astehe P. Aiingona, Philemon A. Agashua, Grace R. Awopetu, \\ Ortese C. Terhemba, Akume B. Iveren
}

\begin{abstract}
This study investigated the perceived role of "Igbe" religious practice in the development of mental illness among the Tiv people of Benue State. The "Igbe" religious practice has been part of the Tiv culture for quite a very long time now and despite attribution of the practice to the development of some mental illness no empirical research has been carried out to substantiate this fact. A quantitative and qualitative design was utilized for the study. A purposeful and convenient sampling technique was used for the study. A total of 1540 participants comprising of $1037(64.8 \%)$ male and $503(31.8 \%)$ female were sampled for the study. The Igbe Inventory a self developed inventory by the researcher for the measure of Igbe and Religious Commitment Scale were used for data collection. Three hypotheses were tested using simple linear regression, independent t-test and chi-square. It was found among others that Igbe religious practice played a significant role in the development of mental illness among the Tiv people. The result also showed a significant age difference on the influence of Igbe religious practice in the development of mental illness among the Tiv people and a significant influence of Igbe religious practice on other ethnic groups in the development of mental illness. Based on the study findings, recommendations were made.
\end{abstract}

Index Terms - Igbe, religious practice and mental illness.

\section{INTRODUCTION}

Mental illness implies deviation from some clearly defined norms of the society. That is why, when any human being changes his/her behavior unexpectedly from the normal way of life, the public construes these signs as mental illness. Many cultures view mental illness as a form of religious punishment or demonic possession. In ancient Egyptian, Indian, Greek, and Roman writings, mental illness was categorized as a religious or personal problem. In the 5th century B.C., Hippocrates was a pioneer in treating mentally ill people with techniques not rooted in religion or superstition; instead, he focused on changing a mentally ill patient's environment or occupation, or administering certain substances as medications. During the middle Ages, the mentally ill were believed to be possessed or in need of religion. Negative attitudes towards mental illness persisted

Astehe P. Aiingona ( Ph.D). Department of psychology Benue State University, Makurdi. Nigeria

Philemon A. Agashua (Prof.) Nigerian Defence Academic Kaduna State. Grace R. Awopetu (Ph.D) Department of psychology Benue State University, Makurdi.

Ortese C. Terhemba (MA) Benue State University, Makurdi. Nigeria Akume B. Iveren(MSc.) University of Mkar Gboko Benue State, Nigeria into the 18th century in the United States, leading to stigmatization of mental illness, and unhygienic (and often degrading) confinement of mentally ill individuals (Linda, 2013).

The concept of illness, either mental or bodily, implies deviation from some clearly defined norms of the society (Szasz, 1960). That is why, when any human being changes his/her behavior unexpectedly and behaves differently from the normal way of life, the public construes these signs as mental illness. These changing behavioral indications are described by Muslims as possessed by 'Peer' and illustrated by Hindus as possessed by 'Goddess' (Behere, 2013). Due to the lack of instruments or devices through which we can measure the exact cause of this changing behavior a lot of causes come into the picture for mental illness. As a result, culture and religion are playing a major part in determining the different causes of mental illness and shape the treatment process accordingly. The people sometimes blame demonic spirits or curse of the past life as the cause of mental illness (Magnier, 2013).The concept of mental illness is changeable over time, but it is specific to culture at a given time in its history (Foucault, 1965; Szasz, 1960).

Substantial body of research has indicated that religious practice is associated with mental illness. Religion of one kind or another has existed in all societies and it has had profound effects on the lives of those who practice it. According to James (1990), religion is a belief in a power superior to man, which is believed to direct and control the course and nature of human life. Malcolm (2001) is of the view that religion can be seen to be the product of psychological factors inherent in all human beings and on the other it is seen as providing support for social values and social stability. He believes that religion originates from the mind out of fear and security for the group cohesion guided by the moral principles of social values to stabilize the social system. Empirical studies have identified significant links between religion and mental health. Religion as a discipline is a matter of great concern for social scientists in general and psychologists in particular since it plays an important role in directing, shaping and moulding social behavior at both the individual level and group levels. Although religion is a universal institution, it affects to a great extent the thought and behavior of individuals living in a multi religious country like Nigeria. Each religion codifies and expresses the cultural values of the society as a whole.

Until recently, religious practices and mental illnesses 


\section{The Perceived Role of "Igbe" Religious Practice in the Development of Mental Illness among the Tiv People of Benue State Nigeria}

were closely aligned. Many of the first mental hospitals were located in monasteries and run by priests. With some exceptions, these religious institutions often treated patients with far more compassion than did state-run facilities prior to 19th century mental health reforms (reforms which were often led by religious persons such as Dorothea Dix and William Tuke). The first form of psychiatric care in the United States was moral treatment, which involved the compassionate and humane treatment of the mentally ill, a revolutionary notion at a time when mental patients were often put on display and/or housed in despicable conditions in the back wards of hospitals or prisons. Religion was believed to have a positive, civilizing influence on these patients, who might be rewarded for good conduct by allowing them to attend chapel services. In the late 19th century, however, the famous neurologist Jean Charcot and his star pupil, Sigmund Freud (1962), began to associate religion with hysteria and neurosis. This created a deep divide that separated religion from mental health care for the next century, as demonstrated by the writings of three generations of mental health professionals from Europe, the United States, and Canada.

Today, however, attitudes toward religion in psychiatry have begun to change. The American College of Graduate Medical Education now states in its Special Requirements for Residency Training for Psychiatry that all programs must provide training on religious or spiritual factors that influence psychological development (Jean, 1986). Part of this change has been driven by scientific research over the past two decades that suggests religious influences need not always be pathological, but can actually represent resources for health and well-being.

Mankind has grown more secular yet religion continues to exert its hold on its psyche. Scientific enquiry has undermined religious beliefs but failed to demolish it (Hugh, 2010). More so, Agber, (2014), admitted that the fact that religion used to form a crucial aspect of identity for majority of Tiv people, it can be asserted that much of the Tiv history can be understood through the interplay among its few religious groups or sects. One of the few and most crucial religions born in Tiv is 'Jôv (Ijôv)', a collection of diverse doctrines, sects, and way of life followed by the great majority of the population. Shishima (2005) identified the Ajôv (plural for Jôv) sects as: IjôvAôndo, IjôvAgeraiber (Agerabyer), IjôvAgabi, IjôvGyariyô and IjôvAkpa, IjôvNyian, IjôvPupuu, Ijôv il, IjôvIhuraVanger, IjôvMnger, $\mathrm{Ku}$ ngu Uma, IjôvAyaba, Wanlisa and Kumendur.Tiv traditional religion can be defined as a Tiv indigenous system of beliefs in 'Aôndo' (God), as manifested in Akombu (Igbe) and practice directed towards the fundamental concern of the Tiv society or nation. Importantly, despite callous attacks by the British colonial and western Christianity on the Tiv Indigenous Religion, its resilience is rewarded by the gluing force of capacitation to solve the culture waning problems of Tiv society which the colonial customs and western Christian religion cannot solve. The early Tiv western Christian converts made countless attempts and resolutions to sweep out completely, the Tiv Indigenous Religious practices and the Tiv culture however, after an eternity of resolutions, doubts, indecisions and the resilience of the Tiv religion murdered their lukewarm machinations that would have towed the tradition into unsolicited silent extinction (Agber, 2014).

Wegh (1998) believed that Tiv religious thought is hinged on three basic concepts. These are Aondo, Tsav and Akombo (Igbe) all of which work together for stability, harmony and communal wellbeing and Lugira (2009) identified Tiv Religion as one of the Central Africa living religions. Waapera (2014) observed that the Tiv religion and culture are intricately intertwined with their cosmology. As a consequence, their religious beliefs, physical and metaphysical conceptions constitute in its entirety, an inseparable worldview. Tiv cosmology basically centers on the existence of Aôndo (God), akombo (Igbe), tsav (witchcraft), azôv and ujijingi (spirits) all conceived as supernatural while, Or and Umache (man and human), Tar (land, district, locality) and Gbaaôndo (nature) are similarly conceived as natural.

In Tiv cultural society "all mental illness is attributed to the violation of a particular "Akombo" for example, "Akombo" "a Igbe" is the protective emblem whose violation results in infection by dysentery" (Hagher, 1989). Indeed, in Tiv mytho-lectics, diagnostic symptoms of mental illnesses and diseases: cough (houghtingir), common cold (gbakundu), whooping cough (hough u bar), fever (iyolhian), malaria (iyolgenger), gangrene (ibya), dysentery, diarrhea (akongu a haan, igbeinyian), diabetes (suga), body aches, paleness of skin, drooping eyelids, anaemia, wiry or falling hair (veekombo); impotence, infertility, hemorrhage, (ikyôôr, akomboadam, akombogbande); rashes, boils, blisters, hard scaly pimples, distended belly, rheumatism, gastronomic disorders and ulcers, sores in the private parts, helpis, etc and other psycho-social maladies of ill-luck, poverty, joblessness, childlessness are all covered by the pantheon of Tiv trado-religious medicare and have appropriate cult discourses associated with the controlling akombo deities.

One can deduce that right from origin the Tiv people had a strong tie with Igbe religious practices to the development of mental illness but no research has ever been carried out to relate these variables to the development of mental illness in Tiv land which is the basis of this research study.

\section{STATEMENT OF THE PROBLEM}

In Tiv land, Igbe cannot be isolated from the development of mental illness. The role of religious practices of Tiv is so much attached to the development and treatment of mental illness that if investigated will add to the knowledge of culture and religious bound syndrome in the field of mental health. Igbe in Tiv land has received a lot of attraction by various researchers in other fields of study, although in the field of clinical psychology no research has so far been carried out concerning Igbe to the development of mental illness which the present study considers as a great lacuna that needs to be filled. Also the Tiv culture, religious practices play a significant role in the development and treatment of mental illness which researchers can search for ways of diagnosis, management and promotion of mental health in Tiv land.

The researcher's desire is for mental health professionals 
to start looking at inward causes and treatment of mental illness rather than totally relying on the Euro-American perspectives. Apart from that, culture and religious practices of a particular ethnic group can bring out new perspectives if investigated in the field of clinical psychology that will help in identifying the etiology of mental illness and how such mental illnesses can be treated. There is every need to find out how Igbe religious practices among the Tiv culture influence the development of mental health as this will go a long way to add to the existing knowledge of the impact of religious practices in the development and treatment of mental illness.

\section{PURPOSE OF THE STUDY}

The purpose of this study is to investigate the perceived role of "Igbe" religious practice in the development of mental illness among the Tiv people of Benue State. Therefore the study aimed at determining (1) the influence of "Igbe" religious practice on the development of mental illness among Tiv people in Benue State (2) if "Igbe" religious practice has influence on the young more than their older counterparts on the development of mental illness among the Tiv people of Benue State (3) if "Igbe" religious practice has influence on other ethnic groups in the development of mental illness. Hypotheses were tested based on the three specific purpose of the study.

\section{METHODOLOGY}

\section{Research Design}

The design of the study is both qualitative and quantitative research design because questionnaires and focus group discussion were applied for data collection. A focus group discussion on Igbe in the MINDA geopolitical zone of the Tiv was carried out by the researcher to elicit information which formed the development of the Igbe instrument that was used for data collection from the participants. Igbe religious practice was the independent variable and mental illness as the dependent variable. The developed instrument was used for data collection in the remaining four geopolitical zones comprising of Jechira, Jemgbagh, Kwande and Sankera respectively.

\section{SETTING}

This research was conducted in the five geopolitical zones of the Tiv speaking areas of Benue State. This is because Igbe deity is mostly peculiar to the culture of the Tiv people but can also affect other tribes. The Tiv form the largest ethnic group in North Central Nigeria and are the largest ethnic group in Benue State. They settled on both banks of the river Benue. The group constitutes approximately $3.5 \%$ of Nigeria's total population, and numbered about 6.5 million individuals throughout Nigeria and Cameroon. The Tiv are the 4th largest ethnic group in Nigeria. Bahannan expresses, that, their home land stretches from approximately $6^{\circ}$ to $100^{\circ}$ east by the Hausa speaking Mada, the Jukun and Chamba, to the North by the Alago and Akwa, to the south by the Udam (Shishima, 1993). The Tiv occupy 14 Local Government Areas, which are as follows; Kwande, Makurdi, Ushongo, Vandiekya, Konshisha, Ukum, Gboko, Logo, Gwer, Gwer West, Guma, Katsina-Ala, Buruku and Tarka respectively.
The Tiv people are basically farmers and the language spoken by them is known as Zwa Tiv ( Tiv Language) with little variation among the various districts. The concept of Aondo (God), Tsav (Witchcraft), Ujijingi (Spirit) and Akombo (Rituals) which Igbe is part of constitute the sum total of Tiv world view, religion permeates all facets of life (Shishima, 1993).

\section{PARTICIPANTS}

The participants for the study comprised of the four selected geopolitical zones of the Tiv areas which include; Jechira, Jemgbagh, Kwande and Sankera. This does not include the MINDA zone because the zone was used by the researcher for pilot study to establish the psychometrics properties for the developed Igbe inventory. The population of the four zones was estimated at 2,451,833 (Census, 2006). Out of the total population of the zones, a sample size of 1600 between the age ranges of 19 to 80 years was used as participants for the study. Out of the total population of the study, $1037(64.8 \%)$ were male while 503(31.8\%) were female and $60(3.8 \%)$ were missing. Also 151(9.4\%) participants had no formal education, $119(7.4 \%)$ had primary education, 251(15.7\%) had secondary education, 1002(62.6) had tertiary education and $77(4.8 \%)$ were missing. Again 284(17.4\%) participants were farmers, 240(15\%) were civil servants, $492(30.8 \%)$ were students, 428 (26.8\%) did not mention occupations and $156(9.8 \%)$ were missing. Furthermore, the marital status of the participants showed that $535(33.4 \%)$ were single, $910(56.9 \%)$ were married, $26(1.6 \%)$ were separated, $43(2.7 \%)$ were widowed, and $86(5.4 \%)$ were missing. In addition, participant's religious affiliation indicated that $1445(90.3 \%)$ were Christians, 26(1.6\%) were Islam, 55(3.4\%) were African traditional religion, other religious were $13(.8 \%)$ and 61(3.8) missing. Lastly, the denominations of the participants showed that, 482(30.1\%) were Catholics, 463(28.9\%) were Pentecostals, $88(5.5 \%)$ were protestants, other denominations were $15(.9 \%)$ and $552(34.5 \%)$ were missing respectively.

\section{SAMPLING}

A convenient and purposive sampling technique (non -probability sampling method) was used for the selection of the 1540 participants who were from the selected four geopolitical zones of the Tiv people because of their convenient accessibility and for the purpose of the research.

\section{INSTRUMENTS}

The study used the following instruments: Igbe inventory and Religious Commitment Scale.

\section{Igbe Inventory}

The Igbe inventory is a self developed inventory by the researcher for the measure of Igbe. The Igbe inventory was developed through a focus group discussion study to elicit information which formed the development of the instrument, and pilot study for validation and reliability of the instrument was conducted using the MINDA group. A focus discussion group was organized by the researcher which assisted in the transcription of the items of the questionnaire 
that was administered to the participants in the MINDA geopolitical area of the Tiv people. The focus group was divided in to three groups, group one comprised of 12 people, group two 7 people, and group three 9 people totaling 27 participants. All the 27 participants were people who had experience about Igbe and have seen the effect of Igbe on Igbe victims. Through the discussion, the researcher took comprehensive notes which helped in the transcription of the focus group discussion to questionnaires. These questionnaires were then re-evaluated by the members of the focus group and validated by different lecturers of Benue State University before it was used for pilot study for reliability testing. The result of the pilot study indicated a reliability coefficient about knowledge of Igbe Cronbach's Alpha of .45 while experience about Igbe indicated a reliability Cronbach's Alpha of .90 and the reliability for all the variables indicated .86 respectively. The result of the pilot study generally indicated a high level of reliability of the Igbe inventory.

\section{The Religious Commitment Scale}

This scale was developed by Worthington, Wade, Hight, Ripley, McCullough, Berry, Schmitt, Berry, Bursley, \& O'Conner (2003). The scale has 10 items to be answered on a five Likert-point ranging from 1 not of all true of me to 5 totally true of me. The scale has a strong internal consistency of .89 with a proven good validity of above .76 respectively. The scale is suitable for use in both mental healthcare and pastoral care. The scale is designed and validated to professional communication about faith and meaning of life.

\section{PROCEDURE}

The researcher travelled to the selected four geopolitical zones of the Tiv people and administered 1540 questionnaires

Table I: Simple linear regression analysis summary table showing the influence of Igbe religious practice in the development of mental illness among the Tiv people in Benue State

\begin{tabular}{|c|c|c|c|c|c|c|c|}
\hline Variables & $\mathbf{R}$ & $\mathbf{R}^{2}$ & $\mathbf{F}$ & $\beta$ & $\mathbf{T}$ & $\mathbf{P}$ & Remark \\
\hline Constant & .553 & .306 & 590.845 & & 22.419 & .000 & \\
\hline Igbe religious practice & & & & .553 & 24.307 & .000 & Sig \\
\hline
\end{tabular}

6

Result in table 1 shows a significant score. It shows the influence of Igbe religious practice in the development of mental illness, the result shows that Igbe religious practice has a significant influence in the development of mental illness $[\beta=-.553, \mathrm{t}=24.397 ; \mathrm{p}<.001]$. Observation further revealed that Igbe religious practice significantly accounted for $30.6 \%$ of the total variance observed in the development

Table II: Independent t-test summary table showing age difference (young and old) in the development of mental illness

\begin{tabular}{|c|c|c|c|c|c|c|c|c|c|}
\hline $\begin{array}{l}\text { Dependent } \\
\text { Variable }\end{array}$ & Group & $\mathbf{N}$ & Mean & SD & SE & $\mathbf{t}$ & Df & $\mathbf{P}$ & Remarks \\
\hline \multirow{3}{*}{ Mental Illness } & Young & 612 & 12.01 & 2.59 & .105 & \multirow{3}{*}{4.090} & \multirow{3}{*}{1359} & \multirow{3}{*}{.000} & \multirow{3}{*}{ Sig } \\
\hline & & & & & & & & & \\
\hline & Old & 749 & 12.61 & 2.80 & .102 & & & & \\
\hline
\end{tabular}

Result in table 11 shows a significant score. It shows that religious practice in the development of mental illness among there is a significant age difference on the influence of Igbe the respondents $[t \quad(1359)=-4.090 ; p<.001]$. Further to the participants at their various residences in the villages among those who had knowledge about Igbe and those who had not. The questionnaires were shared to the participants by the researcher after they were given informed consent forms whom the researcher met to answer the questionnaires declined with the reasons that, they don't want to do anything with the culture of Igbe and this was particularly to people who claimed that their religious doctrines did not allow them to participate in issues that involve traditional affiliation. Apart from that, when people saw that the questionnaires heard about Igbe and didn't want to involve themselves researcher to convince people to participate in the study despite the explanations the researcher gave them about the purpose of the study and assuring them of their safety. In some areas, the participants took the researcher to their chief for more explanation and clarification before they agreed to nswer questionnaires that were given to them.

Data for the study were analyzed using simple linear regression, Independent t-test Chi-Square. Simple linear regression was used to test the influence of Igbe religious practice in the development of mental illness, Independent t-test was used to test age difference (young and old) in the development of mental illness while chi-square was used to test the influence of Igbe on other ethnic groups.

\section{RESULT}

Hypothesis one states that Igbe religious practice will significantly influence in the development of mental illness among the Tiv people in Benue State.

of mental illness. Hypothesis one which stated that "IGBE" religious practice will significantly influence in the development of mental illness among the Tiv people of Benue State' is therefore accepted.

Hypothesis Two states that, the influence of "Igbe" religious practice will significantly differ between the young and their older counterparts in the development of mental illness among the Tiv people of Benue State. were about Igbe, they were afraid because of what they might 
comparism in the age difference shows that older adults (Mean $=12.61, \mathrm{SD}=2.80)$ significantly reported higher influence of Igbe religious practice than their younger counterparts $($ Mean $=12.01, \mathrm{SD}=2.59)$ on the development of mental illness among the respondents in the study area. Hypothesis two which stated that "the influence of "Igbe" religious practice will significantly differ between the young Table III: Chi-square goodness of fit showing the influence of Igbe on other ethnic groups

\begin{tabular}{|c|c|c|c|c|c|c|c|}
\hline Dependent Variable & Group & Observed & Expected & $\mathbf{X}^{2}$ & Df & $\mathbf{p}$ & Remarks \\
\hline \multirow{5}{*}{$\begin{array}{l}\text { Influence of Igbe in the } \\
\text { development of mental illness } \\
\text { among other tribes }\end{array}$} & Tiv & 183 & 309 & \multirow{5}{*}{417.251} & \multirow{5}{*}{4} & \multirow{5}{*}{.000} & \multirow{5}{*}{ Sig } \\
\hline & Idoma & 337 & 309 & & & & \\
\hline & Igede & 295 & 309 & & & & \\
\hline & Itilo & 418 & 309 & & & & \\
\hline & Others & 312 & 309 & & & & \\
\hline
\end{tabular}

and their older counterparts in the development of mental illness among the Tiv people of Benue State' was therefore returned.

Hypothesis three states that "Igbe" religious practice will significantly influence other ethnic groups in development of mental illness.
The result from table 111 shows a significant influence of Igbe religious practice on other ethnic groups in the development of mental illness. It shows that there is a significant influence of Igbe religious practices on other ethnic groups in the development of mental illness $\left[X^{2}(4)=\right.$ 417.251; $\mathrm{p}<.001]$. This result implies that all ethnic groups are significantly influence by Igbe religious practice in the development of mental illness. The hypothesis which stated that "Igbe" religious practice will significantly influence other ethnic groups in development of mental illness' was therefore confirmed.

\section{DISCUSSION OF FINDINGS}

Hypothesis one which states that Igbe religious practice will significantly influence in the development of mental illness among the Tiv people in Benue State was significant. This implies that, Igbe in Tiv culture among other things contribute to the development of mental illness. This finding agrees with Sheikh and Furnham (2000) who examined the relationship between culture beliefs about the causes of mental illness and attitudes associated with seeking professional help for psychological problems. Their finding showed that cultural beliefs were positively related to the causes of mental illness. Also the result of the study is in line with Nalini (2011) who examined cultural and gender influences on mental health, health beliefs, health behavior, help-seeking and treatment expectations for mental health problems in newcomers to Canada who were members of an ethno-cultural, visible minority population -the Sri Lankan Tamils. Her finding showed a significant influence of cultural beliefs on the development of mental illness and other mental health related issues among the people. In addition the result agrees with Michelle and Patrick (2017) who investigated depression in the barrio: An analysis of the risk and protective nature of cultural values among Mexican American substance users. In addition, findings revealed that age is inversely related to depressive symptomatology. Young Mexican American heroin users who do not ascribe to traditional Latino values were highly associated with depression and therefore more vulnerable to riskier drug use behaviors. Moreover, drug-using social networks may affect the protective nature of certain cultural values. Furthermore the finding is in line with Natalio and Natalia (2005) who examined the hypothesis that cultural factors influence the relation between Perceived Emotional Intelligence (PEI) and depression. The finding revealed that depression was fundamentally associated with PEI (20\% of the variance), gender ( $5 \%$ of the variance) and with cultural dimensions (approximately 6\%).

Hypothesis two which states that the influence of "Igbe" religious practice will significantly differ between the young and their older counterparts in the development of mental illness among the Tiv people of Benue State was significant. This implies that, there exists a clear difference between the older people and the younger people towards the influence of Igbe religious practice in the development of mental illness. This finding is in line with a research informant named Tyover (An informant) who categorically postulated that the older people are more prone and affected by Igbe as compared to the younger people for the fact that they have the basic knowledge about the Igbe more than the younger one. Also their old age cannot stand the gravity of the effect of Igbe and are more likely to experience a swift development of mental illness.

Hypothesis three which states that "Igbe" religious practice will significantly influence other ethnic groups in the development of mental illness was significant. This implies that, the effect of Igbe is not only peculiar to the Tiv people but can also affect other tribes that go against it in Tiv culture. This finding agrees with Baba Iorfa (Research informant) who stated that Igbe in Tiv culture knows no tribe when you go against it and cited an example of a British foreigner who was affected by the Igbe in the 1960s during the period of Nigerian colonization. According to him, the Igbe Ivesen can affect other tribes too if they steal or touch something that Igbe emblem is used to protect (yange). He further explained that Igbe has no respect for any one and have the same effect on everybody that goes against it without limitation.

\section{CONCLUSION}

Based on the findings, it is concluded that, Igbe religious practices among the Tiv people have a strong contribution to the development of mental illness. Also the effect of igbe is 


\section{The Perceived Role of "Igbe" Religious Practice in the Development of Mental Illness among the Tiv People of Benue State Nigeria}

not peculiar to the Tiv people alone but cut across individuals from other tribes that violate or go against the Igbe. Finally, the effect of Igbe is more severe on the older people than the younger ones.

\section{RECOMMENDATIONS}

i. Religious practice should always be considered by clinicians when handling issues of mental illness in Tiv land and across other tribes for effective treatment and etiology of mental illness.

ii. Clinical professionals should not only center their clinical practice on Euro-American perspective but should be flexible in their approach to mental health issues that would consider other factors such as cultural and religious practices of the people.

iii. Health professionals should imbibe the culture of searching into their immediate surrounding for the causes and treatment of mental illness rather than relying on foreign knowledge that only focuses on their environment.

\section{LIMITATIONS OF THE STUDY}

i. The research only covered the four geo-political areas in Tiv land which limit the generality of the research findings.

ii. The research centered on only one aspect of culture bound syndrome to the development of mental illness which makes the study limited as there are other culture bond syndromes that also lead to the development of mental illness.

iii. Not all culture-bound syndromes in Tiv culture that have history of mental illness development was captured in the study which makes the research a unidirectional study.

\section{REFERENCES}

[1] Agber, H. (2014). Dynamics of Tiv Religion and Culture. Aphilosophical-Theological Perspective. Lagos: Free Enterprise Publishers.

[2] Behere, P.B., Das, A.,Yadav, R. \& Behere, A.P. (2013). Religion and mental health. India journal of psychiatry, 55, 12,187.

[3] Foucault, M. (1965). Mental illness and psychology. Berkeley, CT: International Universities Press.

[4] Hagher, I. (1989). Performance in Tiv oral poetry In U. N. Abalogu, et. al.(eds.) Oral poetry in Nigeria. Lagos: Emmancon Print.

[5] Hugh, A. (2010). On the Tiv of Central Nigeria: A Cultural Perspective. Ibadan: John Archers Publishers.

[6] James, W. (1990). Varieties of religious experience. New York: Longmans, 1902

[7] Jean, G. (1986). An Introduction to West African Traditional Religion. Ekiti: Omolagyo Standard Press.

[8] Linda, M. R. (2013). The Hormone Factor in Mental Health: Bridging the Mind-Body Gap. Jessica Kingsley Publishers.

[9] Lugira, D. (2009). Religious beliefs and religious delusions: Response to treatment in schizophrenia. Mental Health, Religion \& Culture, 7,211-223

[10] Malcolm, D. (2001). Religion as culture: Religious individualism and collectivism among American Catholics, Jews, and Protestants. Journal of Personality, 75,709 -742.

[11] Magnier, M. (2013). India battles misconceptions on mental illness. Los Angeles Times.

[12] Michelle, N. \& Patrick, K. (2017). Depression in the barrio: An analysis of the risk and protective nature of cultural values among Mexican American substance users. International Journal of Psychology: 2, 23,234-257.
[13] Nalini, P. (2011).Cultural Influences on Help-Seeking, Treatment and Support for Mental Health Problems -A Comparative Study using a Gender Perspective. A thesis submitted in conformity with the requirements for the degree of Doctor of Philosophy Institute of Medical Science University of Toronto.

[14] Natalio, L. \& Natalia, H. (2005). Cultural factors influence the relation between Perceived Emotional Intelligence (PEI) and depression. International Journal of Psychology: 3, 4,56-67.

[15] Sheikh, S. \& Furnham, A. (2000). Across-cultural study of mental health beliefs and attitudes towards seeking professional help. Journal of Social Psychiatry Epidemio, 35, 326-334.

[16] Shishima, D. S. (2005). Unpublished Lecture Note on Spirit World of Africa. Makurdi: Benue State University.

[17] Szasz, T. S. (1960). The myth of mental illness. American Psychologist, 15(2), 113-118.

[18] Waapera, T. (2014). Swem: A Tiv Symbol of Justice, in Shishima, D. S, Journal of Religion and Philosophy3, 2, 34-45.

[19] Wegh, S. (1998). Between Continuity and Change: Tiv Concept of Tradition of Modernity. Enugu: Snaaps Press Limited.

[20] Worthington, E. L., Jr., Wade, N. G., Hight, T. L., Ripley, J. S., McCullough, M. E., Berry, J. W., Schmitt, M. M., Berry, J. T., Bursley, K. H., \& O'Conner, L. (2003). The religious commitment inventory-10: Development, refinement, and validation of a brief scale for research and counseling. Journal of Counseling Psychology, 50, 84-96. 